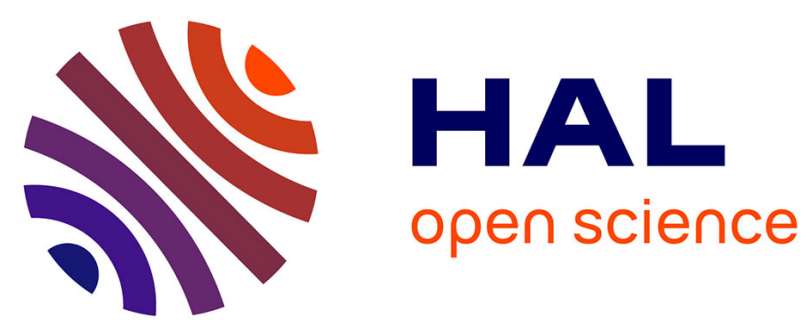

\title{
Variability and reliability of the French version of the Quality of Recovery-40 Questionnaire (QoR-40)
}

Marie Vignaud, Cloé Morel, Antoine Henault, Emmanuel Futier, Bruno Pereira, Céline Lambert, Hélène Beloeil

\section{- To cite this version:}

Marie Vignaud, Cloé Morel, Antoine Henault, Emmanuel Futier, Bruno Pereira, et al.. Variability and reliability of the French version of the Quality of Recovery-40 Questionnaire (QoR-40). Anaesthesia Critical Care \& Pain Medicine, 2021, 40 (2), pp.100822. 10.1016/j.accpm.2021.100822 . hal03190730

\section{HAL Id: hal-03190730 \\ https://hal.science/hal-03190730}

Submitted on 21 Apr 2021

HAL is a multi-disciplinary open access archive for the deposit and dissemination of scientific research documents, whether they are published or not. The documents may come from teaching and research institutions in France or abroad, or from public or private research centers.
L'archive ouverte pluridisciplinaire HAL, est destinée au dépôt et à la diffusion de documents scientifiques de niveau recherche, publiés ou non, émanant des établissements d'enseignement et de recherche français ou étrangers, des laboratoires publics ou privés. 


\section{Variability and reliability of the French version of the Quality of Recovery-40 Questionnaire (QoR-40)}

Marie VIGNAUD ${ }^{\mathrm{*}}$, Cloé MOREL ${ }^{\mathrm{a}}$, Antoine HENAULT ${ }^{\mathrm{b}}$, Emmanuel FUTIER ${ }^{\mathrm{c}}$, Bruno PEREIRA ${ }^{\mathrm{d}}$, Céline LAMBERT ${ }^{d}$, Hélène BELOEIL ${ }^{\mathrm{e}}$

a Département d'Anesthésie et Réanimation, Centre Hospitalier Universitaire (CHU) ClermontFerrand, Hôpital Estaing, 63100 Clermont-Ferrand, France

${ }^{b}$ Département d'Anesthésie et Réanimation, Centre Hospitalier Universitaire (CHU) Rennes,

France

c Département d'Anesthésie et Réanimation, Centre Hospitalier Universitaire (CHU) Clermont Ferrand, Hôpital Estaing, and Université Clermont- Auvergne, CNRS, INSERM U- 1103, 63000 Clermont Ferrand, France

${ }^{d}$ Biostatistic Unit, Centre Hospitalier Universitaire (CHU) Clermont Ferrand, Direction de la Recherche Clinique et de l'Innovation (DCRI), 63100 Clermont-Ferrand, France

e Département d'Anesthésie et Réanimation, Centre Hospitalier Universitaire (CHU) Rennes, France, and Rennes University, INSERM, INRA, Rennes University Hospital, CIC 1414, Rennes, France

*Corresponding author: Marie Vignaud

Pôle de médecine périopératoire, $\mathrm{CHU}$ Estaing, $\mathrm{CHU}$ de Clermont Ferrand, 63100 ClermontFerrand, France

Email: mvignaud@chu-clermontferrand.fr 


\section{Abstract:}

Introduction: The quality of recovery- 40 (QoR-40) is a 40 -item questionnaire. It is widely used and validated in English language for non-major surgery. Its objective is to collect information about quality of recovery in the postoperative period. However, a French version of the QoR40 has not yet been established. The objective of this study was to develop a French version of QoR-40.

Patients and Methods: The translation procedure was established according to Beaton's recommendations to create a French version of QoR-40. 181 patients were enrolled, and each completed the questionnaire the day after surgery, and 6 hours later, and 15 days later. The QoR-40 was compared to morphine consumption in recovery room, and to visual analogue scale. The method of validation for QoR-40 included internal consistency, test-retest reliability, effect size and level of responsiveness.

Results: $99 \%$ of patients answered the full questionnaire at day one. Cronbach's alpha for the global QoR-40 at day one was 0.83 . For the total QR40 total score, Lin's concordance coefficient was $0.78(95 \% \mathrm{Cl}[0.70 ; 0.86])$. The sensitivity to change was determined in 39 patients for an effect-size equals $0.56(95 \% \mathrm{Cl}[0.11 ; 1.02])$.

Conclusion: The French version of QoR-40 seems to be valid, reliable, and acceptable as the original English Version

Keywords: Quality of Recovery 40; French; Post-operative recovery; Questionnaire 


\section{Introduction}

Quality of recovery after anaesthesia is an important measure of the early postoperative health status of patients. Focusing on a limited number of aspects of patient's recovery (i.e. pain and postoperative nausea and vomiting) leads to narrow vision and other sources of patient discomfort might not be considered. Of course, the overall quality of recovery after surgery and anaesthesia should be defined from the patient's perspective. Among all the scores proposed in the literature to measure a patient's global health status after surgery, the 40-item quality-of-recovery scale (the QoR-40) is the most used and validated (1).The QoR-40 is a simple, valid, reliable, and responsive instrument (2). It is a 40 items questionnaire providing a global score across five dimensions: patient support, comfort, emotions, physical independence, and pain. Each item is rated on a 5-point Likert scale, giving a global QoR-40 score ranging from 40 to 200, representing, respectively, very poor to excellent quality of recovery.

QoR-40 has already been translated in several languages including Thai, Arabic, Iranian, Korean (3-6). So far, the French version of QoR-40 has not been validated. Therefore, the aim of the study was to develop a French version of QoR-40 questionnaire by translation and cultural adaptation and to assess the validity and the reliability of the French questionnaire

\section{Patients and methods}

\section{1-Translation procedure}

The translation procedure was performed based on the Beaton's and Bullinge's recommendations to create a French version of the QoR-40 comparable to the original English version (7). In the first step, and after obtaining the authorization of Pr Myles, two French native bilingual translators ( $\mathrm{CM}$ and $\mathrm{EF}$ ) independently translated the QoR-40 into French. Afterwards, a third French native bilingual translator (MV, the initial project manager) 
compared the two translations and checked for inconsistency and adapted the vocabulary. Any discrepancies and differences were resolved by discussion, and finally a consensus version was reached. The next step was a backward translation, the French version was translated into the original English language. The translator was a native English speaker (MH). The authors verified good concordance of English and French versions and checked for grammatical mistakes.

\section{$\underline{\text { 2-Ethics }}$}

The validity and the reliability of the French questionnaire was then assessed in a multicentre prospective observational study in 2 tertiary teaching hospitals in France (Clermont-Ferrand and Rennes). The study was approved by the ethics committee of the French Society of Anaesthesia Intensive Care and Perioperative Medicine (SFAR) (Comité D’Ethique en Anethésie Réanimation- CERAR- ref IRB 0010254-2018-025).

\section{$\underline{\text { 3-Protocol }}$}

Adult patients 18 years of age scheduled for elective general surgery under general anaesthesia were included. The non-inclusion criteria were inability to speak or write French, day-case surgery, inability to understand the questionnaire, patients scheduled for major surgery (cardiac, aortic, hepatic, pancreatic, gastric, intracranial), ASA score of 4.

The study aims were explained to eligible patients the day before surgery, before signing an informed consent. Patients orally answered to the questionnaire when asked by an investigator (A.H in Rennes and C.M in Clermont-Ferrand) 3 times: day one after surgery twice and 6 hours apart to evaluate the test/retest phase and a third time by phone 15 days after surgery to evaluate sensitivity to change.

\section{4- $\underline{\text { Data collection }}$}

At each participating centre, the following data were collected by two investigators (AH and $\mathrm{CM}$ ): Age, gender, ASA score, type and duration of surgery, perioperative opioid 
treatment and morphine consumption at day one were retrieved. The QoR-40 data were also collected:

- Part A includes comfort state (4 items), emotional state (3 items), physical independence ( 5 items) and patient support ( 6 items) and makes a total of 90 points.

- Part B includes comfort state (8 items), emotional state (6 items), patient support ( 1 item), and pain ( 7 items) and makes a total of 110 points. All items are rated on a five-points Likert scale from one (worst) to five (best). The total score was computed by summing all items. The minimum and maximum possible score were 40 and 200, respectively.

\section{5- $\underline{\text { Statistical analysis }}$}

According to Terwee et al. a minimum of 160 patients were needed to conduct to evaluate the internal consistency: "The number of subjects included in a factor analysis is a matter of debate. Rules-of-thumb vary from four to 10 subjects per variable, with a minimum number of 100 subjects to ensure stability of the variance-covariance matrix". A minimum of 50 to 60 patients were needed to conduct the test/retest phase (evaluation of reliability), and a minimum of 30 to 50 were necessary to conduct the sensitivity to change analysis (8). According to these considerations and to recruitment, it was proposed inclusion during 6 months.

The statistical analyses used in this study were those usually used in studies to validate scales (8). In addition to descriptive statistics, the following psychometric properties of the QoR-40 scale were explored using Stata Software (StataCorp, College Station, US).

(i) Acceptability: Data quality was considered satisfactory if more than $95 \%$ of the scale data were fully computable. Score range, closeness of mean to median, floor and ceiling effects, and skewness of score distributions were also analysed. 
(ii) Internal consistency was determined through Cronbach's alpha coefficient (minimum accepted value: 0.70 ); the item homogeneity coefficient (criterion value: $\geq 0.30$ ); and the itemtotal correlation corrected for overlap (criterion value: $\geq 0.30$ ).

(iii) Reproducibility: The Lin's concordance coefficient was used to determine the test-retest reliability of the QUIP-RS scale. Values $\geq 0.70$ were deemed satisfactory (9).

(iv) Hypotheses testing: Regarding convergent validity, relationships between QoR-40 scale score, other quantitative measures of psychological disorders and PD-related measures were studied using correlation coefficient (Pearson or Spearman, according to statistical distribution) (10).

(v) The external validity in comparison to QoR-40 scale was explored using correlation coefficients when items of QoR-40 scale were considered as quantitative outcomes, and usual statistical tests (ANOVA or Kruskal-Wallis tests) when items of QoR-40 scale were considered as categorical outcomes.

\section{Results}

Between May and October 2018, 181 patients were included in this study. Subject characteristics are presented Table 1.

Data on the internal consistency of the QoR-40 scale are displayed on Table 2. Cronbach's alpha coefficient was $0.83[0,79 ; 0,87]$.

Detailed results for QoR-40 questionnaire at day one are shown in Table 3. Time to complete the questionnaire was $5+/-1$ minutes. 
The results for the data quality and acceptability of the QoR-40 scale are displayed in Figure 1. Fully computable data were obtained for $99 \%$ of the sample. The total score of QoR-40 was $166 \pm 16$, with a minimum value at $68(1 / 181,0.6 \%)$ and a maximum at $197(1 / 181$, $0.6 \%)$ for a possible range between 40 and 200 points.

The item-rest correlation are ranged from 0.09 and 0.55 (appearance and well-being respectively) and are presented in table 2 . Inter-items correlations are represented graphically with a color-coded heatmap in figure 2.

Test-retest reliability was determined in 96 patients. For the total QoR-40 total score, Lin's concordance coefficient was $0.78(95 \% \mathrm{Cl}[0.70 ; 0.86])$. The concordance coefficient for items was higher than 0.4, except for "shaking or twitching" and "feeling confused" (respectively 0.4 and 0.39), both in Part B. These results are presented Figure 3

The correlation between QoR-40 and morphine consumption at day one was weak to moderate $(r=-0.11, p=0.14)$, contrary to QoR-40 and visual analogue scale $(r=-0.30, p<0.0001)$. The sensitivity to change was determined in 39 patients. The total score at J0 was $165.8 \pm 14.8$ and $173.9 \pm 13.8$ at J15 ( $p=0.001)$, for an effect-size equals $0.56(95 \% \mathrm{Cl}[0.11 ; 1.02])$. The sensitivity to change for each dimension is presented figure 4 . 
Table 1: Subject characteristics

\begin{tabular}{ll}
\hline Number of subjects & 181 \\
\hline Sex, Women & $114(63 \%)$ \\
\hline Age, Year & $55.7 \pm 16.6$ \\
\hline ASA score & $63(35 \%)$ \\
1 & $80(44 \%)$ \\
2 & $38(21 \%)$ \\
3 & \\
\hline Type of surgery & $12(7 \%)$ \\
Maxillo-facial surgery & $5(3 \%)$ \\
Minor orthopaedic surgery & $56(31 \%)$ \\
Major orthopaedic surgery & $20(11 \%)$ \\
Spine surgery & $4(2 \%)$ \\
Proctologic surgery & $28(15 \%)$ \\
Colorectal surgery & $7(4 \%)$ \\
Wound abdominal surgery & $5(3 \%)$ \\
Bariatric surgery & $5(3 \%)$ \\
Biliary surgery & $6(3 \%)$ \\
Urologic surgery & $7(4 \%)$ \\
Plastic surgery & $4(2 \%)$ \\
Peripheral vascular surgery & $22(12 \%)$ \\
Gynaecologic surgery & $90[60 ; 130]$ \\
\hline Duration of surgery, min & $141(78 \%)$ \\
\hline Intraoperative opioids & $36(18 \%)$ \\
Sufentanyl, & $4(2 \%)$ \\
Remifentanyl & \\
Opioid free anaesthesia & \\
\hline
\end{tabular}


Table 2: Internal consistency criteria

\begin{tabular}{|c|c|c|c|c|c|}
\hline & Item-rest correlation & $\mathbf{N}$ & $\begin{array}{l}\text { Item-test } \\
\text { correlation }\end{array}$ & $\begin{array}{l}\text { Average } \\
\text { Inter item } \\
\text { correlation }\end{array}$ & Alpha \\
\hline Breathe easily & 0,1286 & 181 & 0,1961 & 0,1133 & 0,8329 \\
\hline Good sleep & 0,3372 & 181 & 0,3976 & 0,1094 & 0,8273 \\
\hline Enjoy food & 0,2334 & 180 & 0,2982 & 0,1113 & 0,8301 \\
\hline Feel rested & 0,5056 & 181 & 0,556 & 0,1062 & 0,8226 \\
\hline Well-being & 0,546 & 181 & 0,5936 & 0,1055 & 0,8214 \\
\hline In Control & 0,4783 & 181 & 0,5306 & 0,1067 & 0,8233 \\
\hline Comfortable & 0,5076 & 181 & 0,558 & 0,1062 & 0,8225 \\
\hline Normal speech & 0,32 & 181 & 0,3811 & 0,1097 & 0,8277 \\
\hline Brush teeth & 0,2893 & 180 & 0,3522 & 0,1102 & 0,8285 \\
\hline Appearance & 0,0891 & 181 & 0,1573 & 0,1141 & 0,8339 \\
\hline Able to write & 0,1992 & 181 & 0,265 & 0,112 & 0,831 \\
\hline Return to work & 0,3501 & 179 & 0,4098 & 0,1091 & 0,8268 \\
\hline Communicate with staff & 0,3625 & 181 & 0,4216 & 0,1089 & 0,8265 \\
\hline Communicate with family & 0,2867 & 181 & 0,3493 & 0,1103 & 0,8286 \\
\hline Support from doctors & 0,3377 & 181 & 0,3981 & 0,1093 & 0,8272 \\
\hline Support from nurses & 0,3746 & 181 & 0,4331 & 0,1086 & 0,8262 \\
\hline Support from friends & 0,2267 & 181 & 0,2915 & 0,1114 & 0,8302 \\
\hline Able to understand instructions & 0,2135 & 180 & 0,279 & 0,1117 & 0,8306 \\
\hline Nausea & 0,4629 & 180 & 0,5162 & 0,107 & 0,8238 \\
\hline Vomiting & 0,3389 & 180 & 0,3991 & 0,1094 & 0,8272 \\
\hline Dry- retching & 0,4182 & 180 & 0,4742 & 0,1079 & 0,825 \\
\hline Feeling restless & 0,1343 & 180 & 0,2017 & 0,1132 & 0,8327 \\
\hline Shaking & 0,1928 & 180 & 0,2593 & 0,1121 & 0,8312 \\
\hline Shivering & 0,1347 & 179 & 0,2031 & 0,1132 & 0,8327 \\
\hline Cold & 0,2423 & 181 & 0,3073 & 0,1112 & 0,8299 \\
\hline Dizzy & 0,3896 & 181 & 0,4477 & 0,1084 & 0,8258 \\
\hline Bad Dreams & 0,1858 & 181 & 0,2522 & 0,1123 & 0,8314 \\
\hline Anxious & 0,3824 & 181 & 0,4409 & 0,1085 & 0,826 \\
\hline Angry & 0,2797 & 181 & 0,343 & 0,1105 & 0,8289 \\
\hline Depressed & 0,4664 & 181 & 0,5194 & 0,107 & 0,8237 \\
\hline Alone & 0,3239 & 181 & 0,3852 & 0,1096 & 0,8277 \\
\hline Difficulty falling asleep & 0,3383 & 180 & 0,3985 & 0,1093 & 0,8272 \\
\hline Confused & 0,1921 & 179 & 0,258 & 0,1121 & 0,8312 \\
\hline Moderate pain & 0,1601 & 180 & 0,2269 & 0,1127 & 0,8321 \\
\hline Severe pain & 0,3197 & 179 & 0,3806 & 0,1097 & 0,8277 \\
\hline Headache & 0,2468 & 180 & 0,3108 & 0,1111 & 0,8297 \\
\hline Muscle pain & 0,2376 & 179 & 0,3018 & 0,1112 & 0,83 \\
\hline Back Ache & 0,2458 & 179 & 0,3097 & 0,1111 & 0,8298 \\
\hline Sore Throat & 0,275 & 180 & 0,338 & 0,1105 & 0,8289 \\
\hline Sore Mouth & 0,3365 & 180 & 0,3968 & 0,1094 & 0,8273 \\
\hline
\end{tabular}


Table 3: QoR-40 at Day one

\begin{tabular}{|c|c|c|c|}
\hline Variable & P25 & Median & P75 \\
\hline Part $A / 90$ point $(n=181)$ & 70 & 75 & 81 \\
\hline Comfort Part $A / 20$ point $(n=181)$ & 13 & 15 & 17 \\
\hline Emotions Part A/ 15 points $(n=181)$ & 10 & 12 & 14 \\
\hline Physical Independence/ 25 points $(n=181)$ & 17 & 21 & 22 \\
\hline Patient Support Part A/ 30 points $(n=181)$ & 27 & 30 & 30 \\
\hline Part B/ 110 points $(n=181)$ & 88 & 94 & 98 \\
\hline Confort Part B $/ 40$ points $(n=181)$ & 34 & 36 & 37 \\
\hline Emotions Part B/ 30 points $(n=181)$ & 24 & 6 & 28 \\
\hline Patient Support Part B /5 points $(n=179)$ & & & \\
\hline Pain /35 points $(n=181)$ & 25 & 28 & 31 \\
\hline
\end{tabular}




\section{Figure 1a}

Red Curve: Floor effect of each item of part A of QoR-40 questionnaire (percentage of patients responding most favourably to the item)

Black cure: Celling effect of each item of part A of QoR-40 questionnaire (percentage of patients responding most negatively to the item)

Histogram: Mean response of the item (on a five-point Likert scale- from 0 "none of the time" to 5 "all the time"

Figure 1b

Red Curve: Floor effect of each item of part B of QoR-40 questionnaire (percentage of patients responding most favourably to the item)

Black cure: Celling effect of each item of part B of QoR-40 questionnaire (percentage of patients responding most negatively to the item)

Histogram: Mean response of the item (on a five-point Likert scale- from 0 "none of the time" to 5 "all the time"

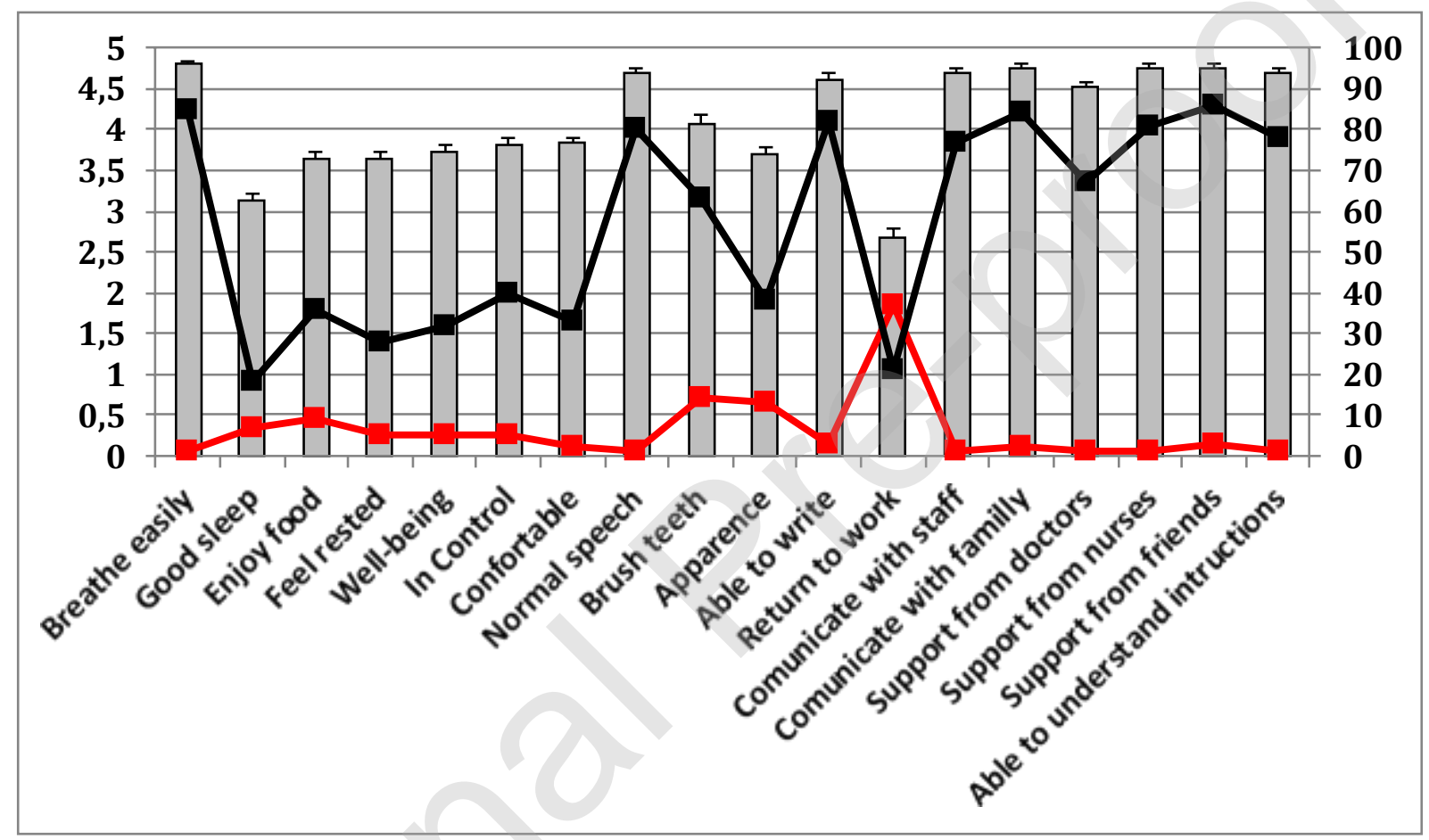




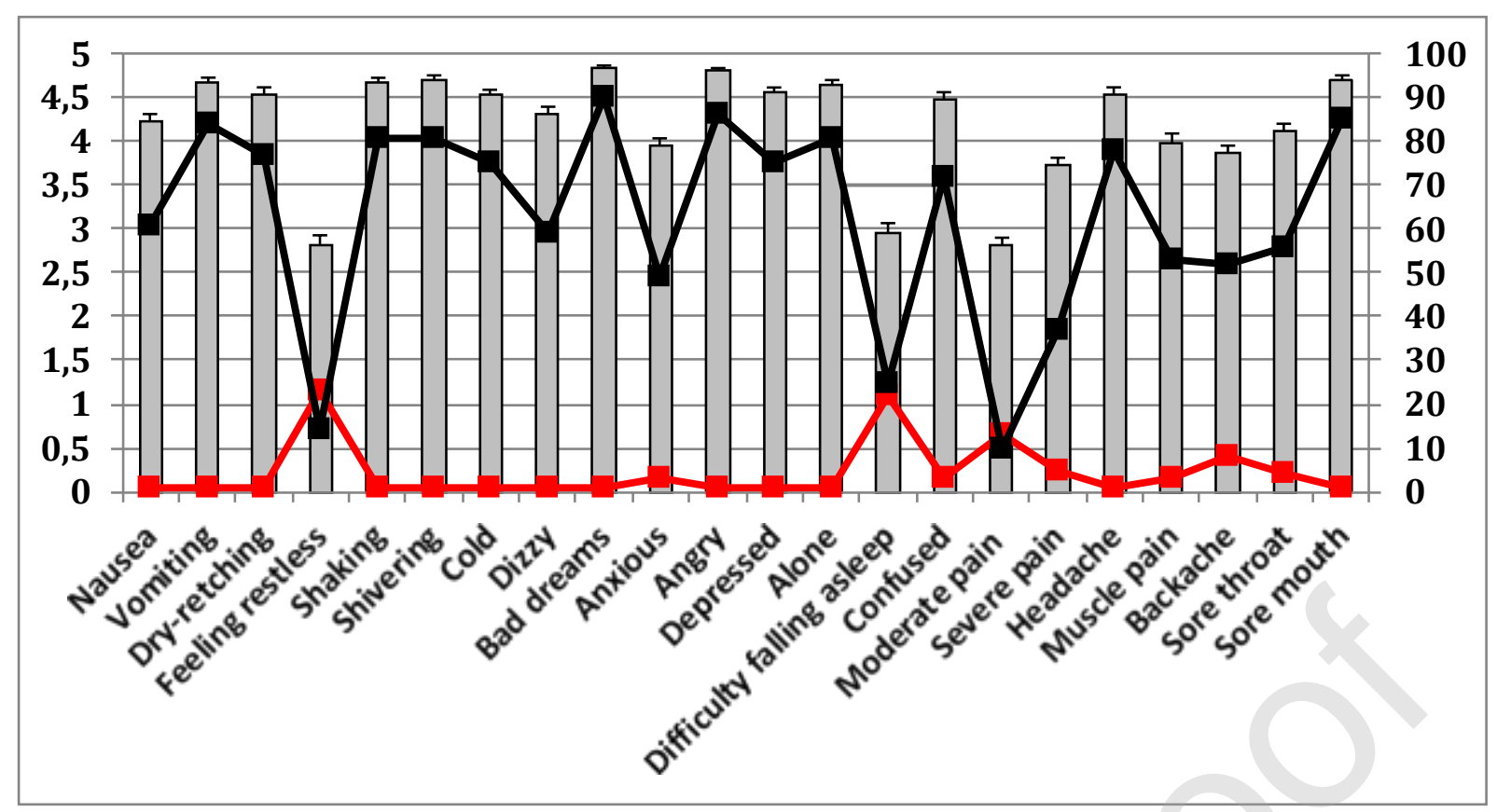


Figure 2 : Collor-coded heatmap describing QoR-40 inter- items correlations

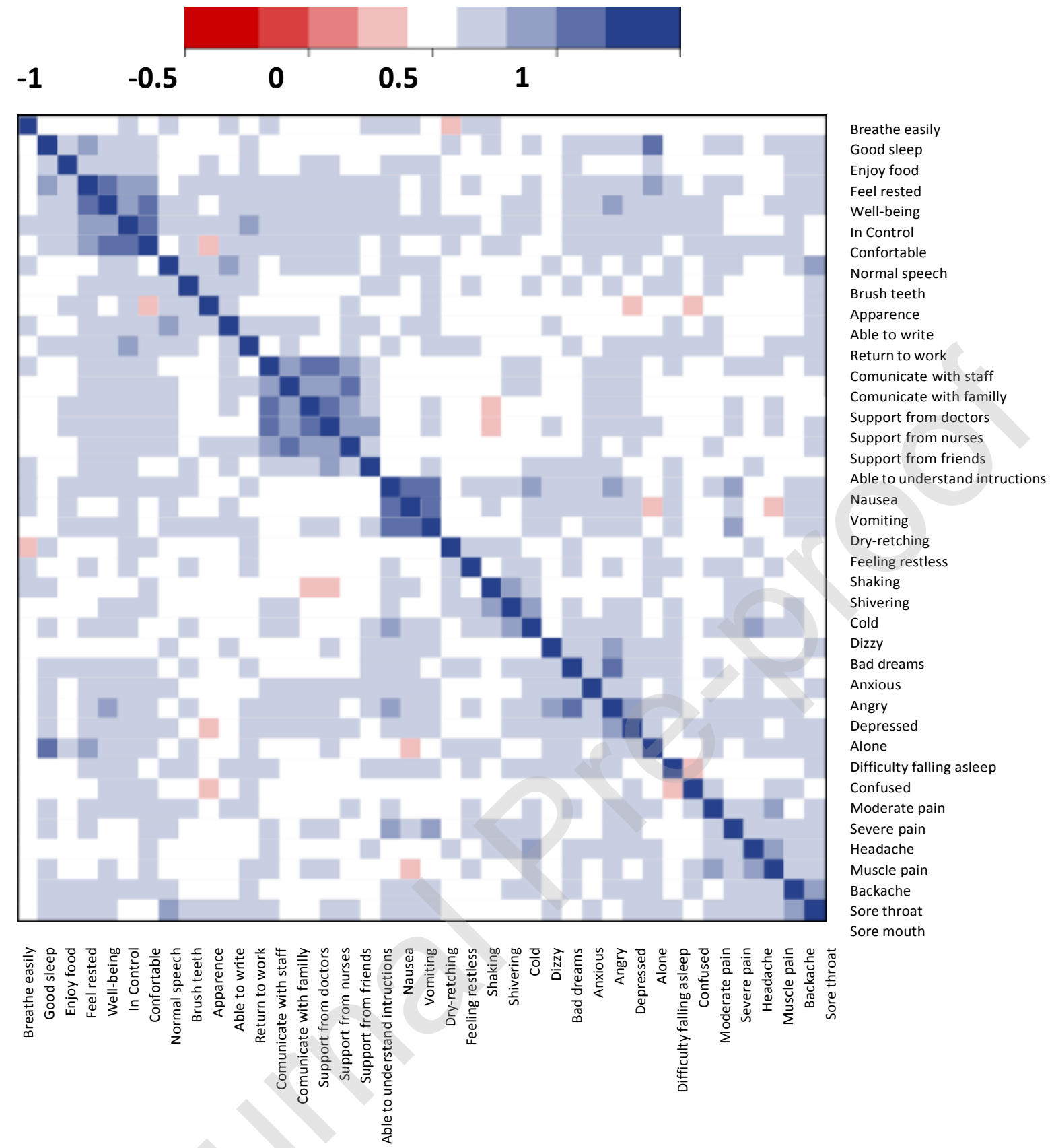


Figure 3a and 3b. Lin's concordance coefficient for QoR-40 re-test items.
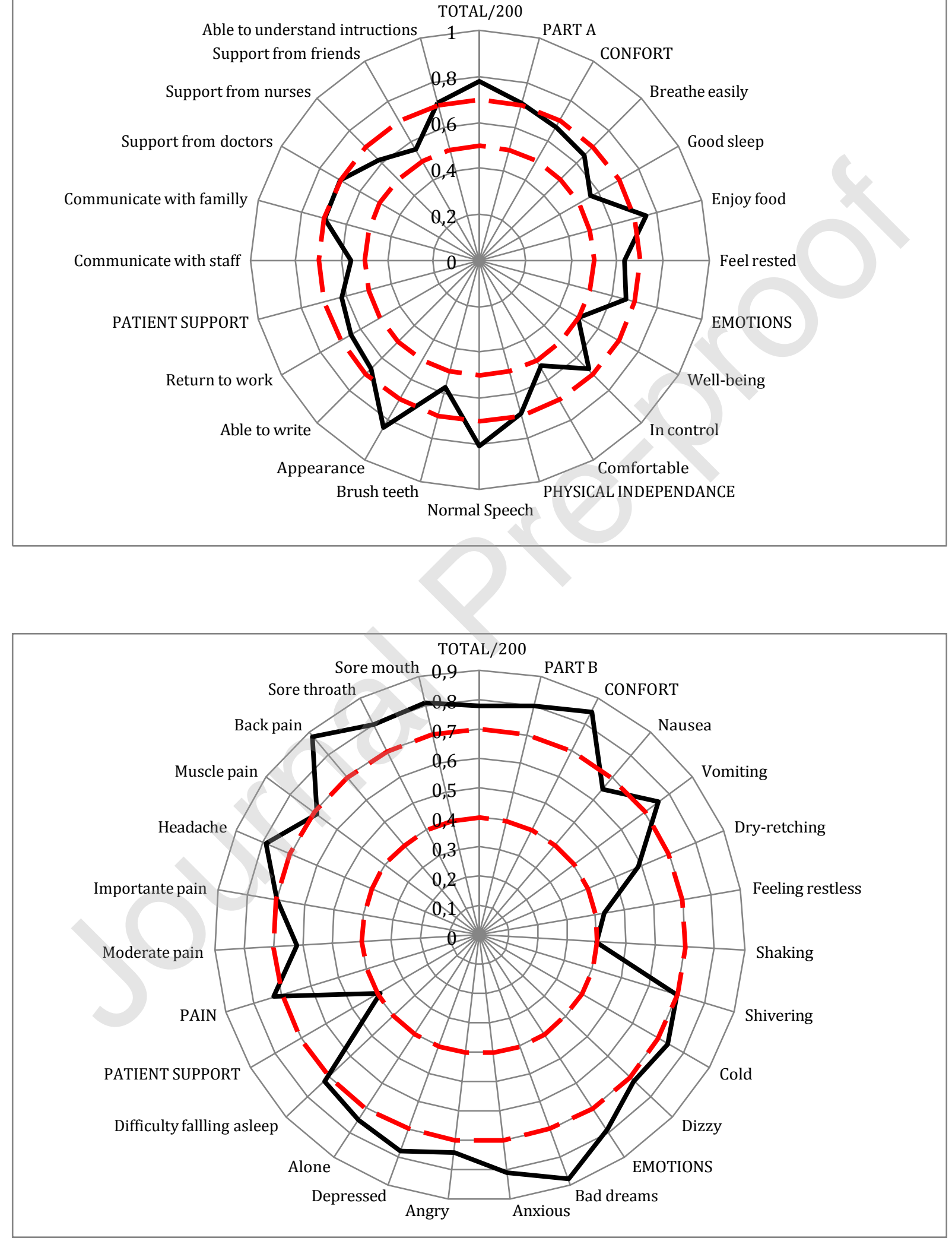
Figure 4: Effect size of each dimension of QoR-40.

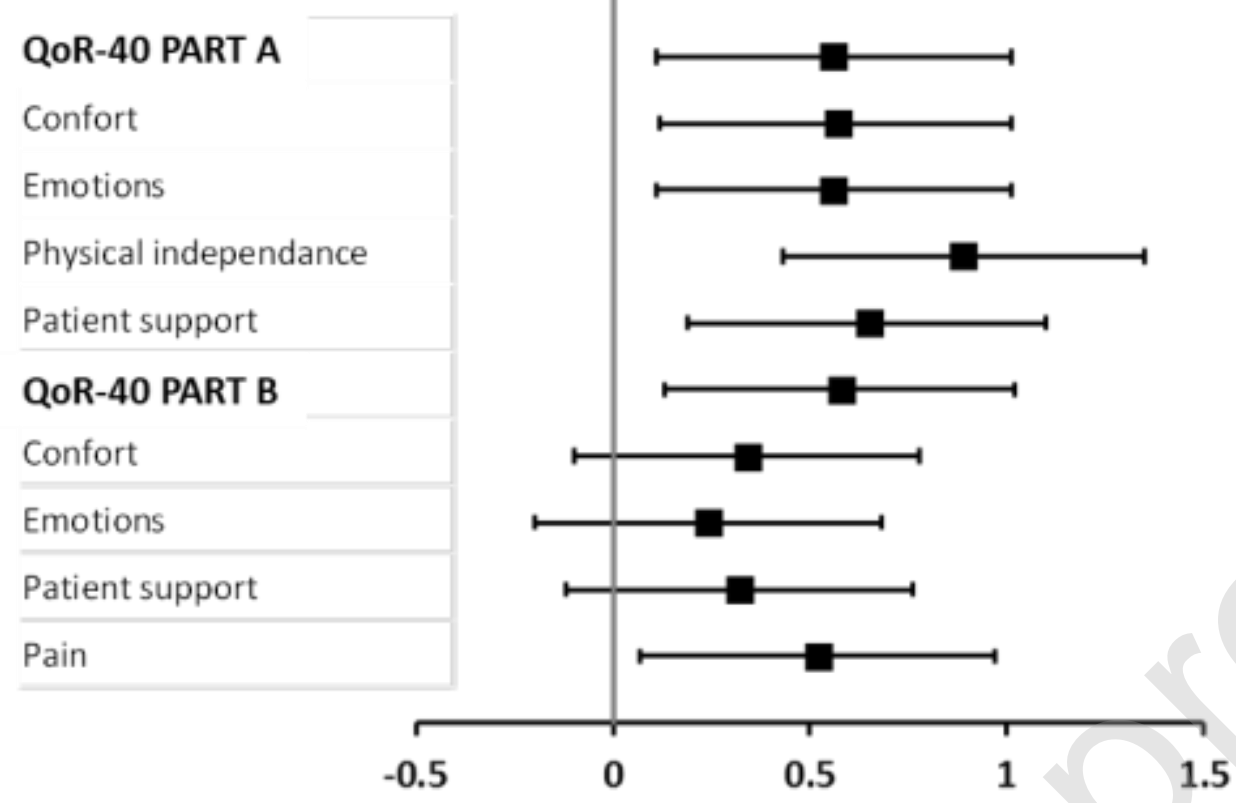




\section{Discussion}

Our study demonstrated a good validity and reliability of our French Version of the Quality of Recovery-40 Questionnaire with a Cronbach's alpha of $0.83[0,79 ; 0,87]$. QoR-40 could be used for French patients after general anaesthesia.

Few tools are available in current practice to evaluate global recovery after general anaesthesia. As example, SF-36 was validated for cardiac surgery (11), SF-8 for ambulatory knee surgery (12) and SF- MPQ-2 for non-specific acute pain (13). To date, the QoR-40 is the only validated score providing information about comfort, emotion, and pain after surgery. The acceptability of the French version of the QoR-40 was excellent (179 over 181 patients answered every 40 items of the questionnaires, and there were few missing datas for the two other patients). A ceiling effect was observed because a proportion of patients did not experience the highest score on some items ("return to work", "feeling restless" and "falling asleep"), which is coherent with clinical events one day after surgery. Internal consistency parameters met the standard criteria; variables of the QoR-40 were positively correlated even if the strength of relationship was low to moderate.

Regarding Test/retest and construct validity, Lin's concordance coefficient test was 0.78 for total QoR-40 questionnaire, suggesting a substantial concordance. All coefficients were above 0.4, except two items, "shaking or twitching" and "feeling confused" (respectively 0.4 and 0.39). The explication could be a translation mistake, or for the second item, a real confusion. It may be a bias of the study.

Reproductibility was excellent for the item "physical independence" of part A, moderate for global part A and B, "comfort part A", "emotions part A", "patient support part A" and "pain part B"; and weak for "comfort part B", "emotions part B" and "patient support part B". In our study, we choosed to evaluate sensitivity to change 15 days after surgery because we hypothesised that most of the postoperative perturbations should have return to normal at 
this time. Effect size showed a moderated sensitivity to change for both Part A et B of the questionnaire. Surprisingly, this indicator was never evaluated in the other validation QoR-40 papers.

Correlation between QoR-40 and morphine consumption at day one were weak to moderate, while Myles and al. reported a good convergent validity (2). Several explanations can be evocated: there was several differences between the populations of our studies: our population was older, and repartition of surgeries were different -more general surgery in Myles's study and more orthopaedic and ENT surgery in our study- then we can evocate cultural differences in pain evaluation between Anglo Saxon and French populations. This enhances the fact that QoR-40 is a use full toll to evaluate the quality of recovery, which is not reduced to the evaluation of pain in the recovery room.

Moreover, French validation of QoR-40 could be useful in program of enhanced rehabilitation after surgery.

Time to complete the questionnaire was about five minutes, which seems relevant in the context. Same durations were found in the literature $(6,14)$. Equivalent durations were found in a summary version of QoR-40, the QoR-15 ( with 15 items questionnaire), supporting using QoR-40 in routine clinical practice $(15,16)$.

Our study has several limitations. First, our population is predominantly female, and composed for $45 \%$ of orthopedic and spine surgery. Then, we did not report marital and education status of our population, which could have been relevant in the context. Finally, contrary to other papers, we did not evaluate correlation between QoR-40 and an other questionnaire of quality of life, like Short-Form-36 (SF-36) $(6,14)$. 


\section{Conclusion}

We propose that the French version of QoR-40 is a valid, reliable, and acceptable to evaluate quality of recovery for French speaking patients after general anaesthesia. II could be a very relevant criterion for studies to come up.

Conflict of interest: none

\section{Acknowledgments:}

We thank Ms Miranda Hobes, a professional English bilingual translator, for helping us creating a French version of QoR-40. 


\section{References}

1. Gornall BF, Myles PS, Smith CL, Burke JA, Leslie K, Pereira MJ, et al. Measurement of quality of recovery using the QoR-40: a quantitative systematic review. Br J Anaesth. 2013;111(2):161-9.

2. Myles PS, Weitkamp B, Jones K, Melick J, Hensen S. Validity and reliability of a postoperative quality of recovery score: the QoR-40. British journal of anaesthesia. 2000;84(1):11-5.

3. Terkawi AS, Tsang S, Abolkhair A, Alsharif M, Alswiti M, Alsadoun A, et al. Development and validation of Arabic version of the Short-Form McGill Pain Questionnaire. Saudi journal of anaesthesia. 2017;11(Suppl 1):S2-S10.

4. Park H, Lee KS, Park YJ, Lee DJ, Lee HK. Reliability and validity of the Korean version of organizational justice questionnaire. Annals of occupational and environmental medicine. 2018;30:26.

5. Pitimana-Aree S, Udompanthurak S, Lapmahapaisan S, Tareerath $\mathrm{M}$, Wangdee A. Validity and reliability of quality of recovery-35 Thai version: a prospective questionnairebased study. BMC anesthesiology. 2016;16(1):64.

6. Yaghoobi S, Hamidfar M, Lawson DM, Fridlund B, Myles PS, Pakpour AH. Validity and reliability of the Iranian version of the quality of recovery-40 questionnaire. Anesthesiology and pain medicine. 2015;5(2):e20350.

7. Beaton DE, Bombardier C, Guillemin F, Ferraz MB. Guidelines for the process of cross cultural adaptation of self-report measures. Spine. 2000;25(24):3186-91.

8. Terwee CB, Bot SD, de Boer MR, van der Windt DA, Knol DL, Dekker J, et al. Quality criteria were proposed for measurement properties of health status questionnaires. Journal of clinical epidemiology. 2007;60(1):34-42.

9. Landis JR, Koch GG. The measurement of observer agreement for categorical data. Biometrics. 1977;33(1):159-74.

10. Fitzpatrick R, Davey C, Buxton MJ, Jones DR. Evaluating patient-based outcome measures for use in clinical trials. Health technology assessment. 1998;2(14):i-iv, 1-74.

11. Myles PS, Viira D, Hunt JO. Quality of life at three years after cardiac surgery: relationship with preoperative status and quality of recovery. Anaesthesia and intensive care. 2006;34(2):176-83.

12. Bost JE, Williams BA, Bottegal MT, Dang Q, Rubio DM. The 8-item Short-Form Health Survey and the physical comfort composite score of the quality of recovery 40-item scale provide the most responsive assessments of pain, physical function, and mental function during the first 4 days after ambulatory knee surgery with regional anesthesia. Anesthesia and analgesia. 2007;105(6):1693-700, table of contents.

13. Dworkin RH, Turk DC, Trudeau JJ, Benson C, Biondi DM, Katz NP, et al. Validation of the Short-form McGill Pain Questionnaire-2 (SF-MPQ-2) in acute low back pain. The journal of pain : official journal of the American Pain Society. 2015;16(4):357-66.

14. Karaman S, Arici S, Dogru S, Karaman T, Tapar H, Kaya Z, et al. Validation of the Turkish version of the Quality of Recovery-40 questionnaire. Health Qual Life Outcomes. 2014;12:8.

15. Kleif J, Edwards HM, Sort R, Vilandt J, Gogenur I. Translation and validation of the Danish version of the postoperative quality of recovery score QoR-15. Acta Anaesthesiol Scand. 2015;59(7):912-20.

16. Lyckner S, Boregard IL, Zetterlund EL, Chew MS. Validation of the Swedish version of Quality of Recovery score -15: a multicentre, cohort study. Acta Anaesthesiol Scand. 
2018;62(7):893-902. 